\title{
The endogeneity of the natural rate of growth in the regions of
}

\author{
Italy \\ Matteo Lanzafame \\ Department of Economics \\ University of Kent
}

\begin{abstract}
Following León-Ledesma and Thirlwall (2002a), this paper investigates the extent to which the natural rate of growth of the Italian regions is endogenous, in the sense that it is affected by actual growth. The estimation framework is based on one version of the cyclical relationship between unemployment and output growth known as Okun's Law [Okun (1962)]. Econometrically, the main hypothesis being examined regards the presence of non-linearities in Okun's Law, which can be interpreted as structural shifts in the natural growth rate. Using annual data over the period 1977-2003, we find strong support for the endogeneity hypothesis when applying the theory-based estimation methodology proposed by LLT. The results are less clear-cut when we switch to a data-driven approach centred on the Hansen's (1997) testing procedure for threshold models. Furthermore, in line with recent findings in the literature, our analysis provides evidence of asymmetries in Okun's Law, suggesting that unemployment turns from counter-cyclical when growth is slow to acyclical or even (in some cases) pro-cyclical in booms.
\end{abstract}

JEL Classification: O40, O18, E23, E10

Keywords: Endogenous growth, Okun's Law, Italian regions

Acknowledgements: I would like to thank, without implicating, Prof. Tony Thirlwall and Dr. Miguel León-Ledesma for helpful comments and suggestions. The usual disclaimers apply.

Department of Economics, University of Kent, Canterbury, Kent CT2 7NP, United Kingdom. Phone: 00441227 827639, Email: M.Lanzafame@kent.ac.uk 


\section{The endogeneity of the natural rate of growth in the regions of Italy}

\section{Introduction}

Regional growth disparities are a persistent feature of the Italian economy. Output growth in Italy has averaged about 2 per cent in the last three decades, with a standard deviation across the regional annual means of about 0.3. If the average growth rate over such a period of time is a good approximation of an economy's trend or natural growth rate, the average Italian region's long-run output growth rate can be expected to be between 1.7 and 2.3 per cent. The difference between the two extremes of this growth band may not seem too important on a year to year basis, but one may take a different view when considering its long-run implications. With an average growth rate of about 2.3 per cent, Lazio's output nearly doubled in the last 30 years while, growing at annual average of about 1.7 per cent, it will take 11 more years for Sardegna's to do the same.

What factors determine the likelihood that one or the other scenario will occur? In other words, what are the determinants of growth in the long-run? Neoclassical growth theory provides a straightforward answer to this question, suggesting that the growth rate of output which an economy converges to in the long-run is entirely dependent on the growth rates of technical progress, which determines that of labour productivity, and the labour force. In the benchmark neoclassical growth model both of the latter rates are assumed as exogenous, implying that the long-run or natural rate of growth is exogenous too, completely determined on the economy's supply side.

If for a policy maker such a conclusion is somewhat disheartening, from a theoretical viewpoint it is rather unsatisfactory. Not surprisingly, a number of alternative theoretical approaches have, in various ways, attempted to "endogenise" growth, ranging from the “Cumulative Causation” school promoted by Kaldor (1966) to the more recent New Growth Theory models [see, among others, Barro (1991), Grossman and Helpman (1991), Lucas (1988), Romer (1986, 1990)]. By and large, these attempts have been successful in highlighting several possible channels via which policy and/or demand-side variables can affect long-run growth, so much so that the question most growth theorists are now debating is (not whether but) to what extent and in what way growth is endogenous. 
This paper is devoted to the examination of this issue in relation to the Italian regions' growth experience. Specifically, using regional annual data over the period 1977-2003, we take as our main reference the work of León-Ledesma and Thirlwall (2002a) (hereafter LLT) and investigate the hypothesis that the natural rate of growth $\left(g_{N}\right)$ of the Italian regions may, under certain conditions, be endogenous to actual growth, so that it may be influenced by demand-side factors as well ${ }^{1}$.

In carrying out our analysis, we start off in the first part of the paper following closely the procedure proposed by LLT which, as will be illustrated, relies on the estimation of a version of Okun's Law [Okun (1962)] to obtain an estimate of $g_{N}$. In so doing, however, we suggest and introduce a correction to it which, following the recent literature on the presence of non-linearities in Okun's Law [e.g. Crespo Cuaresma (2003)] allows for an asymmetric Okun coefficient over the business cycle. This turns out to have significant implications as regards the cyclical pattern of unemployment in booms. In the second part of the paper we switch from the theory-based LLT approach to a data-driven one. Relying on the estimation and testing procedures for threshold models developed by Hansen (1996, 1997, 2000), we search for the presence of non-linearities in output growth and use the results from this analysis in combination with the insights from the work by LLT to further investigate the endogeneity hypothesis.

The remaining part of the paper is organised as follows. Section 2 reviews the theoretical literature on the natural rate of growth and lays out the details of the LLT procedure. The latter is put to the test in Section 3, while Section 4 provides a discussion of the results in relation to recent developments in the literature on Okun's Law and on the cyclical pattern of unemployment. The Hansen procedure is briefly illustrated in Section 5 and applied in Section 6, where the further testing of the endogeneity hypothesis as well as of the non-linear nature of Okun's Law is also carried out. Finally, Section 7 concludes.

\section{The endogeneity of the natural rate of growth: Theory and the LLT estimation approach}

Though partly anticipated by Keynes (1937), the concept of the natural rate of growth was formally introduced in growth theory by Harrod (1939), who defined it as the sum of the

\footnotetext{
${ }^{1}$ For simplicity, in what follows we will sometimes refer to this as the "endogeneity hypothesis".
} 
exogenously given growth rates of the labour force and labour productivity. In the Harrod model the natural rate of growth gives the long-run growth rate of the economy, as well as the short-term constraint on the divergence between the actual and the warranted growth rates in boom periods. It is, thus, both the trend growth rate that the economy oscillates about and the short-term upward limit to growth, which turns cyclical expansions into recessions.

The well-known knife-edge behaviour of the Harrod model, clearly at odds with the empirical evidence, attracted a great deal of criticism and gave rise to a heated debate in the growth literature between the Neoclassical and the Keynesian schools of thought. The ensuing contributions from both sides showed that the Harrodian predictions hinged on the particular assumptions of the model and that the conflict could be resolved by amending the theory ${ }^{2}$. Interestingly, however, the assumption of an exogenous natural rate of growth was not rejected by either approach, nor has it generally been questioned ever since.

Indeed, reflected in the exogenously given steady-state growth rate that economies are predicted to gravitate about, the Harrodian assumption of an exogenous natural growth rate has since become customary in growth models. The widely accepted implication is that demand-driven variations of actual output are always short-lived, as only supply shocks can have permanent effects on output growth.

LLT question the legitimacy of this proposition. They argue that there are many reasons to believe that the natural growth rate may in fact be, to some extent, endogenous and react positively to changes in the actual growth rate, as both the growth rate of labour productivity and that of the labour force are likely to be affected by significant swings in economic activity brought about by changes in demand.

The conjecture of a positive functional relation between the growth rate of output and that of labour productivity is hardly new in the literature. Embodied in the so-called Verdoorn's Law [Verdoorn (1949)], such a causal link is, for instance, at the basis of models in the cumulative causation tradition, as put forward by Dixon and Thirlwall (1975) and León-Ledesma (2002), among others. In this context, the presence of learning by doing [Arrow (1962)] and/or static and dynamic macro-economies of scale [Young (1928)] have been advanced as explanations for the positive association between output growth and productivity growth. More recently, similar ideas have been used in building models of

\footnotetext{
${ }^{2}$ In particular, the neoclassical school questioned the assumption of a constant capital-labour ratio, implicit in the Harrod model. If capital-labour substitutability is allowed, the capital-output ratio will adjust to bring into equilibrium the warranted and natural growth rates. The Keynesian camp, on the other hand, obtained the same result focusing on adjustments to the savings ratio, brought about by changes in the distribution of income between wages and profits.
} 
endogenous business cycles in which, because of pro-cyclical technological progress, the evolution of output is portrayed as being partly dependent on itself [e.g. Stadler (1990), Blackburn (1999), Fatás (2000)].

These theories have not gone unchallenged, as opposite arguments have also been put forward which suggest a counter-cyclical pattern of technological progress and/or productivity growth. Among these is the idea that cyclical slumps may have a "cleansing effect” on the economy, ridding it from the most inefficient units and, thus, raising average productivity [Caballero and Hammour (1994)]. More generally, it has been argued that, because of the lower opportunity cost in terms of forgone production, recessions are characterised by the reallocation of resources towards long-run productivity-enhancing activities, such as training, human capital accumulation, the introduction of new technologies [Saint-Paul (1997)]. Thus, the suggestion in this case is that the determinants of long-run growth reflect the Schumpeterian forces of “creative destruction” [Schumpeter $(1939,1950)]$.

While the sign of the relation is, thus, still matter of an unresolved theoretical debate, not least because of inconclusive empirical evidence, both approaches concur in assuming the existence of a causal relation between output and productivity growth. The implication is that, not only real but also demand shocks can affect trend productivity growth and, thus, alter the long-run path of output. As a result, the treatment of short- and long-run growth as two essentially unrelated phenomena is challenged at its roots.

Several factors can also be pointed at to support the hypothesis that labour force growth responds positively to output growth. The empirical evidence shows that hours worked are pro-cyclical and so are labour force participation rates. Furthermore, migration theories as well as historical and current evidence on labour migration flows, both intra- and international, also confirm that buoyant economies tend to attract migrant workers, thus providing a further growth-induced increase of their labour supply [e.g. Massey et al. (1993), Hatton and Williamson $(1998,2002)]$.

Overall, therefore, there is now a substantial body of theoretical and empirical work questioning the exogenous-growth assumption. More precisely, what is currently more explicitly doubted is the relative safeness of this hypothesis. In fact, even if one accepts as sound the arguments regarding the endogeneity of labour productivity and labour force growth to the growth of output, what can be (and has been) argued is that such relations, though present, are not strong enough to affect the trend of long-run growth significantly ${ }^{3}$.

\footnotetext{
${ }^{3}$ This attitude is well summed up by Blanchard and Quah (1989) in their study of the dynamic effects of demand and supply disturbances. In discussing their interpretation of temporary and permanent disturbances
} 
As mentioned, LLT take a different view and suggest that, under certain conditions, faster growth in the short-run can lift the natural growth rate. Specifically, LLT think of the positive relations between output growth and the growth rates of productivity and the labour force as being characterised by switches between low and high growth regimes. Labour productivity and labour force growth are non-continuous functions of the growth rate of output, as the above-described mechanisms which make them endogenous come into play only when the actual growth rate rises above the natural rate of growth. In other words, the relation between the actual and the natural growth rates is a non-linear one, subject to a threshold effect which determines the switch between the growth regimes ${ }^{4}$. In such a context, a reliable estimate of the threshold, i.e. the natural rate of growth, assumes a key importance and LLT propose an empirical framework to ascertain it.

Building on Thirlwall (1969), LLT note that, since the natural rate is defined as the sum of the growth rates of labour productivity and the labour force, unemployment will rise whenever the actual rate of growth $\left(g_{t}\right)$ falls below the natural rate, while it will fall when $g_{t}$ rises above $g_{N}$. That is, the natural rate of growth is that particular growth rate consistent with a non-changing unemployment rate. Thus, they suggest that a simple estimation technique to pin down the value of $g_{N}$ is to rely on the following specification of Okun's Law

$\Delta \% U_{t}=\alpha_{1}-\beta_{1}\left(g_{t}\right)$

In equation (1) the percentage change in the unemployment rate at time $t$ is expressed as a linear function of the growth rate of output, so that, setting $\Delta \% U_{t}=0$, an estimate of the natural rate of growth can be retrieved as $\alpha_{1} / \beta_{1}$.

The use of this approach, however, is problematic. Thirlwall (1969) and LLT argue that, because of the likely dependence of labour force participation on the growth rate of output and the effects of labour hoarding, the estimates of both $\alpha_{1}$ and $\beta_{1}$, the so-called Okun

to output as, respectively, demand and supply shocks, they argue that, among other things, "The presence of increasing returns, and of learning-by-doing, also raises the possibility that demand disturbances may have some long-run effects. [...] We agree that demand disturbances may well have such long-run effects on output. However, we also believe that if so, those long-run effects are small compared to those of supply disturbances. To the extent that this is true then, our decomposition is "nearly correct"..." (p. 659).

${ }^{4}$ On these issues, see the comment by Boggio and Seravalli (2002) and León-Ledesma and Thirlwall’s (2002b) reply. 
coefficient, may be downward-biased. Furthermore, note that a significant $\alpha_{1}$ would imply the presence of a deterministic trend in the unemployment rate and, though it can in some cases be a reasonable simplification to approximate the behaviour of the unemployment rate in the short- or medium-term, this is an implausible assumption in the long-run. Thus, both theoretical and empirical considerations suggest that estimation of equation (1) may produce insignificant results ${ }^{5}$.

To overcome these drawbacks, LLT propose reversing the dependent and independent variables in (1) and estimate

$g_{t}=\alpha_{2}-\beta_{2}\left(\Delta \% U_{t}\right)$

Setting $\Delta \% U_{t}=0$, one can see that the estimate of $\alpha_{2}$ from equation (2) will be equal to the natural rate of growth. Estimation of (2), however, poses some problems of its own, as the assumed endogeneity of $\Delta \% U_{t}$ means that the coefficient estimates will again be biased.

Having obtained a reliable estimate of the natural rate, one can proceed to testing the endogeneity hypothesis. LLT suggest introducing a dummy variable $(D)$ in equation (2) to allow for a differential intercept whenever the actual growth rate is higher than the natural. That is, they estimate

$g=\alpha_{3}-\beta_{3}(\Delta \% U)+\lambda_{3} D$

where

$D=\left\{\begin{array}{cc}1 & g_{t}>g_{N} \\ 0 & \text { otherwise }\end{array}\right.$

${ }^{5}$ A separate concern regards the first-difference form in which Okun's Law is specified in equation (1). As noted by Attfield and Silverstone (1997), if both output and unemployment are I(1) variables as well as cointegrated, equation (5.1) will be misspecified. Most alternative formulations and estimations of Okun's Law rely on cyclical measures of both output and unemployment, usually obtained via some filtering procedure (e.g. Hodrik-Prescott filter), but these methods have also been criticised as being “ad hoc” [e.g. by Lee (2000)]. A further alternative is represented by the structural time series approach proposed by Harvey (1985, 1989), which builds upon the unobserved component model to decompose each series into its constituting components (i.e. trend, cyclical, seasonal, irregular). However, though promising, this method is not viable in our case because of the short and low frequency (annual, as opposed to quarterly or monthly) time series at our disposal. Thus, in keeping with LLT, we opt for the first-difference model. 
In such a framework, the endogeneity hypothesis will be supported if $\lambda_{3}$, the coefficient of the intercept dummy $D$, is significantly different from zero.

One problem with equation (3) is that, as the introduction of only an intercept dummy illustrates, the switch between the low- and high-growth regimes is held to give rise solely to a level shift in the relationship, while the slope coefficient, assumed to be negative, remains unaffected. If this assumption is wrongly imposed, the estimation of equation (3) will be subject to an additional source of bias which may significantly affect the results. As will be discussed later on, the growing body of empirical evidence on the asymmetric behaviour of the Okun's coefficient suggests that this may well be the case. More generally, as there is no obvious reason for the threshold effect to give rise exclusively to a level shift in the relation between output growth and the percentage change in unemployment, the assumption should be formally tested.

Specifically, the estimated threshold $g_{N}$ should be used to construct intercept as well as slope dummy variables and these should be employed in testing the endogeneity hypothesis via the regression of

$g_{t}=\alpha_{3}+\beta_{3}\left(\Delta \% U_{t}\right)+\lambda_{3} D+\theta_{3}\left(D \Delta \% U_{t}\right)$

where, $D$ is the intercept dummy defined in (4) and $D \Delta \% U_{t}$ is the slope dummy on the percentage change of unemployment. In the single-equation setting, the constant-slope assumption can then be tested according to the significance of $\theta_{3}$, while in the case of a system regression framework, such as that relied upon in this paper, the general model formalised in (3') should be tested against its restricted version (3). We will follow this approach throughout our empirical work.

\section{Testing for the endogeneity of the natural rate of growth in Italy using the LLT approach}

Using annual data on the Italian regions over the years 1977-2003, in this section we proceed to the empirical investigation of the natural growth rate endogeneity hypothesis applying the LLT approach. 
The regional GDP series is taken from the CRENoS database ${ }^{6}$, while the unemployment series has been reconstructed relying on data collected by ISTAT, the Italian national statistical agency, through its "Quarterly Labour Force Survey” (Rilevazione Trimestrale sulle Forze di Lavoro, RTFL) ${ }^{7}$.

Both the regional context which our analysis relates to and the characteristics of our dataset point to the use of a Panel Data approach as the most suitable. We will, thus, follow this route and base our econometric work primarily on the use of Least Square Dummy Variables (LSDV) and system regression techniques ${ }^{8}$.

We start by estimating the set of LLT equations (1) - (3) and equation (3’) via LSDV. Given the characteristics of the theoretical approach under analysis, as typified in particular in equations (2), (3) and (3'), the regional $g_{N}$ 's can be naturally interpreted as capturing regionspecific features. Thus, we exclude a priori the random-effect model on theoretical grounds and rely on the fixed-effect LSDV estimator, which models cross-sectional differences allowing for unit-specific intercepts.

Table 1 reports the LSDV estimates of the natural rate from equations (1) and (2) and the associated estimates from equation $(3)^{9}$. We give preference to the latter specification rather than equation (3') as $\theta_{3}$, the coefficient on the slope dummy variable $D \Delta \% U_{t}$, turns out to be not significant, suggesting the hypothesis of a common slope coefficient in the two growth regimes cannot be rejected. In all cases, the LSDV estimations revealed significant individual as well as time effects, so that the two-way error component model was relied upon.

For each one of the four estimations, the Wald test cannot reject the null hypothesis that the variables are jointly significant, while there is some evidence of serial correlation (of the second order) only for equation (1). The $\mathrm{R}^{2}$ is about 40 per cent in the case of equations

\footnotetext{
${ }^{6}$ CRENoS is the Centro Ricerche Economiche Nord Sud (Centre for North South Economic Research). Detailed information about it and the CRENoS database is available online at http://www.crenos.it.

${ }^{7}$ The design of the RTFL survey and its definition of unemployment have undergone various changes over the years which, since an official ISTAT reconstruction for the entire period is not as yet available, create some complications for empirical work. In our case, two modifications introduced in 1984 and 1992 create two breaks in the series which, whenever necessary throughout the econometric work in this paper, will be dealt with via the use of two impulse dummy variables. All the relevant information on the RTFL can be found on the ISTAT website at http://www.istat.it/.

${ }^{8}$ As a preliminary step, we ran ADF unit root tests on $g_{t}$ to check for the possible non-stationarity of output growth and these rejected the null of a unit root in all cases, except that of Lombardia. However, visual inspection of a plot of Lombardia's $g_{t}$ revealed the likely presence of a break in 1994. The application of Perron's (1997) unit root test with structural breaks rejected the unit root null at the 5 per cent level. The results are reported in Table A.1 in the appendix to this paper.

${ }^{9}$ Throughout this paper, standard errors and/or t-values are not reported, so as not to clutter the reading of the tables with too much information. They are available from the author upon request.
} 
(1) and (2), but the introduction of the intercept dummy $D$ in equation (3) substantially increases the explanatory power of the model.

As regards the Okun's Law approach, the average of the estimated regional natural rates of growth is nearly 4 per cent but, at conventional significance levels, the Wald test indicates that only 7 out of the 20 estimates of the regional $g_{N}{ }^{\prime} s$ are significant.

\section{TABLE 1}

Estimation of equation (3) produces more clear-cut results. All of the variables are significant at the 1 per cent level and have the expected sign. In particular, the intercept dummy variable $D$ is always strongly significant, supporting the hypothesis that the natural growth rate is pulled up by a higher actual growth rate of output. The estimate of the coefficient on the intercept dummy $D$ indicates that the natural rate of growth rises by nearly 3 percentage points in the upturn of the business cycle, making for an average boom $g_{N}$ of more than 5 per cent. Furthermore, if one takes the usual North-South distinction, it can also be noted that the average boom $g_{N}$ is about 0.6 percentage points higher in the Mezzogiorno than in the North ${ }^{10}$. The reliability of these results, however, is weakened by their dependence on the estimated natural growth rates from equation (1) which, as noted, turn out to be not significant in most cases.

Thirlwall's reversal approach performs better in this respect, as the LSDV regression of equation (2) provides strongly significant estimates of the natural rate. Contrary to what was noted for the Okun's equation results, the estimated $g_{N}$ 's are fairly homogenous across regions and, more specifically, there is no difference between the average Northern and Southern values. The average natural growth rate across all regions is now slightly lower (about 3.6 per cent), but the coefficient on the dummy variable $D$ is slightly bigger and so is the average natural rate in boom periods (about 5.1 per cent).

Thus, except for the problems encountered with equation (1), the LSDV results provide fairly strong support for the endogeneity hypothesis put forward by LLT. However, reflecting the panel nature of the data, the LSDV estimator imposes the restriction of common slope coefficients for all the cross-sections, on the assumption that unit-specific characteristics

\footnotetext{
${ }^{10}$ The North and South average boom natural rates of growth are, respectively, 4.8 and 5.4 per cent.
} 
can be appropriately modelled using individual intercepts. For the same reasons, the common$\lambda_{3}$ restriction is also imposed.

These assumptions may be too strong in our case so that, making use of Seemingly Unrelated Regression (SUR) techniques, we investigate the impact of the potential crosssectional heterogeneity on the LSDV results for the single regional equations. Correcting for and exploiting cross-sectional correlation to increase the efficiency of the estimates, in a regional framework such as ours, the SUR approach is likely to be a more suitable alternative to the LSDV estimator than the single-equation estimation approach followed by LLT.

We, thus, proceed as follows. We start by regressing equation (1) via SUR and formally test for any possible combination of cross-equation restrictions, relying on the Likelihood Ratio (LR) test and the multivariate versions of the Akaike and Schwarz Information Criteria (henceforth, respectively, AIC and SIC) to choose the most appropriate model specification. The obtained estimate of the natural rate of growth is, thus, used to construct the intercept and slope dummy variables $D$ and $D \Delta \% U_{t}$ to be introduced in equations (3) and (3'). Next, we apply SUR to the latter equations, again carrying out formal tests for any possible cross-section restrictions on the two systems of equations to choose the model which best fits the data. Once the most appropriate specification for both equation (3) and equation (3') has been selected, we perform the final step of our analysis, which entails testing the restriction $\theta_{3}=0$. The whole procedure is then repeated using equation (2) instead of (1).

\section{TABLE 2}

Table 2 reports the results obtained using the Okun's Law approach. For the estimation of equation (1), both the AIC and the SBC select the most restricted model as the one providing the best fit of the data, while the LR test supports this result failing to reject the null hypothesis of common intercepts and slopes, i.e. of a common natural rate of growth for all regions ${ }^{11}$. The coefficient on $\beta_{1}$ is rather small, but has the expected sign and is significant at the 1 per cent level. According to the appropriate Wald test, so is the estimated $g_{N}$, which turns out as being slightly greater than 3 per cent.

\footnotetext{
${ }^{11}$ This result is likely to depend on the abovementioned drawbacks of equation (1). Indeed, estimation of the unrestricted model shows that in many of the 20 regional equations neither the intercept nor the $\beta_{1}$ parameter turn out to be significant.
} 
The associated estimations and testing involved in the comparison between all possible specifications of equations (3) and (3'), conducted following the aforementioned procedure, results in the selection of the common- $\lambda_{3}$ equation (3') model as the one providing the best fit of the data. The implication is that the size of the level shift of the natural rate of output in boom periods is homogenous across regions, so that the model allows for crosssectional heterogeneity in all parameters except that on the intercept dummy variable.

According to the estimated $\lambda_{3}$, the natural growth rate of output of the Italian regions raises by about 3.7 per cent in boom periods, from an average of about 1.1 per cent in the slow-growth regime to nearly 4.8 per cent, which is fairly close to the correspondent LSDV average estimate (about 5.1 per cent). The estimate of the slow-growth regime natural rate of growth is not significant only in the case of Calabria, while the boom $g_{N}{ }^{\prime} s$ turn out to be strongly significant for all regions, again supporting the LLT view. The slope dummy variable is significant in 14 cases, albeit only at the 10 per cent level in the case of Valle d'Aosta. Interestingly, in 10 out of these 14 instances the $\theta_{3}$ coefficient takes a positive sign and in 9 out of these 10 cases, the exception being Emilia Romagna, this gives rise to a significantly positive Okun coefficient in the high-growth regime.

\section{TABLE 3}

Turning to Thirlwall's reversal approach, both the information criteria and the LR test select the unconstrained model as the most suitable for estimation of equation (2). The results, reported in Table 3, show the estimates of the regional natural growth rates as being all significant at the usual significance levels. The average $g_{N}$ is about 2.2 per cent, which is roughly 0.8 percentage points lower than the corresponding Okun’s Law estimate ${ }^{12}$.

\section{TABLE 4}

\footnotetext{
12 One slight worry related to the estimates in Tables 2 and 3 is that the DW statistic falls in the indecisive region in several cases, as well as signalling the presence of serial correlation in regressions for Calabria and Sicilia of equation (2). To address this, we ran OLS on the 20 individual regional equations (1) and (2) and compare the results, reported in Tables A2 and A3 in the appendix to this paper, to the corresponding SUR estimates. Significant autocorrelation was found only in a handful of cases and we dealt with it applying autocorrelation-robust standard errors and trying out dynamic specifications. The results did not change.
} 
The selection of the best model between all the possible cross-sectionally restricted specifications of equations (3) and (3') results in the choice of the common- $\theta_{3}$ equation (3') model, which assumes that the slope change from one growth regime to the other is homogenous across regions. The estimates, reported in Table 4, are once more in favour of the endogeneity hypothesis.

The $\lambda_{3}$ parameter is always strongly significant and so is the estimated natural rate of growth in boom periods, while the slow-growth-regime $g_{N}$ turns out to be significant in 15 out of 20 cases (one only at the 10 per cent level). The average values of these estimates are broadly consistent with those from coming from the Okun's Law approach, though slightly smaller. The estimated $\theta_{3}$ is significant and positive, again giving rise to a pro-cyclical unemployment rate in booms for 8 regions. This is a somewhat surprising result, whose possible determinants and implications will be discussed in the next section.

To summarize, when put to the test using LSDV and SUR estimations, the hypothesis put forward by LLT as regards the endogeneity of the natural rate of growth is largely supported by the data in the case of the Italian regions. Both the estimators provide fairly homogenous results as regards the change in the natural rate when $g_{t}>g_{N}$, as the estimates of the coefficient on the intercept dummy $D$ are always positive and strongly significant, with values ranging between about 3 and 3.7 percent $^{13}$. However, allowing for complete flexibility in terms of parameter changes between the two growth regimes, the SUR regression estimates of the regional boom- $g_{N}$ 's turn out to be about 0.4 and 1.1 percentage points smaller than their LSDV counterparts. Moreover, they provide evidence for the presence of significant asymmetries in the relation between output growth and unemployment, with the latter turning out to be pro-cyclical in booms in several cases.

\section{Asymmetries in Okun's Law and pro-cyclical unemployment}

The finding of a significantly different Okun coefficient across growth regimes is not new in the literature. Several recent studies on the presence of non-linearities in Okun's Law provide support for the existence of an asymmetric Okun coefficient [e.g. Lee (2000), Silvapulle et al. (2004), Viren (2001)]. Though somewhat mixed, in most cases the empirical evidence on this

\footnotetext{
${ }^{13}$ It is worth noting that the comparable figure estimated for Italy as a whole by LLT is about 3.3 per cent (see LLT, Table 5, p. 451).
} 
asymmetry is in the sense of unemployment reacting always inversely to output changes, but more strongly so in the downturn of the cycle than in the upturn. For instance, using US quarterly data for the period 1965:1-1999:1, Crespo Cuaresma (2003) finds that "Cyclical unemployment is (approximately twice) more responsive to contemporaneous economic growth when the latter is in the 'recessionary' regime” (ibid., p. 449) and that, when using HP-filetered data, the Okun's coefficient drops to only about -0.07 in the high-growth state (ibid., Table 4).

Thus, the finding of a positive coefficient on the slope dummy variable in equation (3') is not in itself surprising. What, to our knowledge, represents a novelty is that the size of the $\theta_{3}$ parameter is big enough so as to make for a significantly positive Okun coefficient in the high-growth regime. When this is so, as it proves to be in 40 to 45 per cent of the cases in our estimations, the switch from one growth state to the other alters not only the intensity of the relation between unemployment changes and output growth, as pointed out in the justmentioned literature, but also its nature, going from countercyclical (or absent) when growth is slow to pro-cyclical in boom periods. When considered against the empirical backdrop on the counter-cyclical behaviour of unemployment, this result is clearly problematic.

Useful insights in dealing with its interpretation can be drawn from a fairly recent strand of the job-search and matching literature. More specifically, a number of recent papers in this area [e.g. Tripier (2002), Shimer (2004), Veracierto (2004)] show that existing models of equilibrium unemployment with endogenous labour market participation generate a procyclical unemployment rate, thus providing a suitable theoretical background for the investigation of the potential determinants of this outcome. The basic intuition provided by these models is that pro-cyclical unemployment may result because, while a growing economy and higher wages attract an increasing number of workers into the labour force in the upturn of the cycle, job search and matching requires time, so that unemployment initially rises, until new market participants become employed.

Haefke and Reiter (2006) examine the conditions under which this result will obtain and propose a job-market matching model with endogenous labour supply which is capable of producing a strongly countercyclical unemployment rate. The key assumption of the model is that the representative agents' decisions as to whether participate in the labour market or not are primarily determined by the difference between their market and home productivities. The solution to the utility maximisation problem is, thus, characterised by a threshold level $h^{c}$ at which the non-employed are indifferent between searching for a job or not, while they will 
participate in the labour market only if their home productivity is strictly lower than $h^{c}$. Therefore, the higher the market productivity with respect to $h^{c}$, the greater the influx of new market participants so that, when growth accelerates after, for instance, a positive productivity shock, the labour force increases.

Haefke and Reiter's (2006) calibration of the model shows that the cyclical pattern of unemployment hinges crucially on the cross-sectional density of the distribution of home productivity levels at the participation threshold. The higher this density is, the greater the number of potential new market participants which will enter the labour force following a positive shock and, thus, the more likely the occurrence of a pro-cyclical unemployment rate. This likelihood falls at higher frequencies of the unemployment data considered (e.g. annual as opposed to quarterly), as this allows more time for matching and unemployment decreases as the new job market participants gradually find employment. A third important factor producing a negative correlation between unemployment and output is a strong response of labour market tightness to output growth. To make this point, Haefke and Reiter (2006) compare a flexible-wage version of the model to one in which some real wage rigidity is allowed for and show that the latter significantly improves the likelihood of counter-cyclical unemployment. This is so because in the upturn of the cycle real wage rigidity makes for an increasing share of profits, thus increasing the firms' incentives to hire and labour market tightness.

In our view, this theoretical debate about the cyclical pattern of unemployment can be enriched of a further valuable dimension if the possible presence of non-linearities, such as those considered in this paper, is introduced into the picture. The results presented in the previous section suggest that the cyclical pattern of unemployment is strictly linked to the presence of asymmetries in Okun's Law. More specifically, they show that while imposing a linear relation on Okun's Law yields the expected negative sign for the elasticity of unemployment to output, consistent with the empirical evidence, once the relation is split between low- and high-growth regimes there is significant evidence of a pro-cyclical pattern in booms.

Arguments akin to those considered within the job-search literature can help explain this outcome. For instance, if the wage-rigidity assumption seems reasonable in a low-growth state, it becomes less defensible when growth rises above the natural rate, so that the likelihood of pro-cyclical unemployment increases. Similarly, the capital-labour ratio is likely to rise in a high-growth regime as, with an increasingly tighter labour market, faster real wages and labour costs growth will give firms more incentives to substitute capital for labour 
and match the increase in demand raising labour productivity, rather than employment. Again, this will increase the probability of a positive relation between unemployment and output in the high-growth scenario.

While these and other factors may determine both the asymmetric behaviour of the Okun coefficient and the counterintuitive pattern of cyclical unemployment in booms, opposite theoretical arguments can also be made as to which sign the output-unemployment relation should be expected to take in the two growth regimes, as reviewed for instance by Silvapulle et al. (2004). This is, thus, ultimately an empirical question.

As the econometric work carried out in the previous section shows, the LLT approach to assessing the endogeneity of the natural rate of growth provides a suitable framework to address these issues from an empirical viewpoint. Nevertheless, LLT's is a fundamentally theory-driven procedure, subject to some drawbacks. In particular, if the endogeneity hypothesis is correct, equations (1) and (2) will be mis-specified, as both assume a linear relationship between the variables concerned. Thus, quite independently from the problems ascertained by LLT, both equations will provide a biased estimate of the natural growth rate, as there is not a single $g_{N}$ but two ${ }^{14}$.

Thus, as an alternative to the LLT procedure, in what follows we adopt a data-driven approach to testing for the endogeneity hypothesis and the presence of asymmetries in Okun's Law. In so doing, we will rely on work carried out in a series of papers by Hansen (1996, 1997, 2000), who develops an econometric framework to deal with the estimation and testing of threshold models ${ }^{15}$. More specifically, focusing directly on the hypothesis at the centre of our investigation in this paper, we will fit univariate models of output growth to the Italian regions and test for the presence of a significant threshold ${ }^{16}$. The results from the threshold tests will be then used to assess the implications of any significant non-linearity for the endogeneity hypothesis and Okun’s Law.

\footnotetext{
${ }^{14}$ To some extent, LLT recognise these problems when, as a more data-based solution, they propose to take the natural rate to be equal to a 3-to-5 year moving-average of the actual growth rate.

${ }^{15}$ Hansen (1999) has further developed the approach and proposed a technique for threshold regressions in the context of non-dynamic panel data models, which is also potentially suitable for our purposes. However, the latter is based on the assumption of a homogenous threshold across cross-section units (e.g. regions). Theoretical considerations and the evidence gathered in the previous section suggest that this may be too strong an assumption in our case, so that we opt for the single-equation procedure.

${ }^{16}$ As the models and ideas just illustrated point to existence of non-linearities in the relation between labour force and output growth, ideally we would complement our analysis tackling such a relation as well, and/or using the LLT equations (1) and (2). Unfortunately, the presence of the abovementioned definition breaks in the labour market data series at our disposal prevents us from carrying out these tests using labour force or unemployment data.
} 


\section{The Hansen threshold estimation approach}

Following Hansen (1997), consider the following threshold autoregressive (TAR) model

$y_{t}=x_{t}^{\prime} \alpha I\left(q_{t-1} \leq \gamma\right)+x_{t}^{\prime} \beta I\left(q_{t-1}>\gamma\right)+e_{t}$

where $I(\cdot)$ is the indicator function, $x_{t}(\gamma)=\left(x_{t}^{\prime} I\left(q_{t-1} \leq \gamma\right) x_{t}^{\prime} I\left(q_{t-1}>\gamma\right)\right)^{\prime}$, $x_{t}=\left(\begin{array}{llll}1 & y_{t-1} & \ldots & y_{t-p}\end{array}\right)^{\prime}$ with $p \geq 1$ indicating the autoregressive order, $q_{t-1}=\left(y_{t-1}, \ldots ., y_{t-p}\right)$ is the threshold variable and $\gamma$ is the unknown threshold parameter.

The sample observations are split into two groups (e.g. growth regimes) and the model coefficients are allowed to vary depending on whether $q_{t-1} \leq \gamma$ or $q_{t-1}>\gamma$. Setting $\theta=\left(\alpha^{\prime} \beta^{\prime}\right)^{\prime}$, one can rewrite (5) as

$$
y_{t}=x_{t}(\gamma)^{\prime} \theta+e_{t}
$$

Conditional on $\gamma$, equation (6) is linear in $\theta$ so that Least Squares (LS) estimation is appropriate $^{17}$. Chan (1993) and Hansen (2000) recommend using sequential conditional Least Squares (LS) to obtain the estimates of the regression parameters $(\theta, \gamma)$. Specifically, for each of the values taken up by the threshold variable $q_{t-1}$, the threshold regression model (6) is estimated and the sum of squared errors $S_{n}(\gamma)$ is obtained. The LS estimate $\hat{\gamma}$, then, is the one that minimises $S_{n}(\gamma)$.

Once the estimate of the threshold $\hat{\gamma}$ is obtained, the coefficient estimates can be computed as $\hat{\theta}=\hat{\theta}(\hat{\gamma})$. To ascertain the significance of the threshold effect, one can simply test the linear constraint $H_{0}: \alpha=\beta$. However, as under the null the threshold $\gamma$ is not identified, the classical F-test does not have a standard distribution. We follow the bootstrap procedure proposed by Hansen (1996) to construct asymptotically valid p-values for the hypothesis test.

\footnotetext{
${ }^{17}$ Note that under the additional assumption that $e_{i}$ is iid $N\left(0, \sigma^{2}\right)$, LS is equivalent to maximum likelihood estimation.
} 


\section{Threshold effects, the endogeneity hypothesis and Okun's Law}

In this section we apply the Hansen threshold test to the Italian regions' growth rates of output ${ }^{18}$, using annual data over the period 1978-2003. We set $p=1$, as the general-tosimple testing carried out shows that an autoregressive process of order one appropriately describes the short-run dynamics. To ensure the model is identified for all the possible values of the threshold, we follow Andrews (1993) and Hansen (1996) in trimming the bottom and top 15 per cent quintiles of threshold variable, so that the search for a threshold is restricted to 70 per cent of the observations.

We use two different definitions of the threshold variable, i.e. either $q_{t-1}=g_{t-d}$ or $q_{t-1}=\Delta g_{t-d}$. The first choice is a standard delay lag, while the second corresponds to the Momentum-TAR or M-TAR model proposed by Enders and Granger (1998) and reflects the idea that the appearance of nonlinearities in output growth might be triggered by an acceleration of growth above a certain threshold rate. The delay lag $d$ is estimated together with the remaining parameters in equation (6). Though we performed the tests using values of $d$ up to 5, only the results for $d$ up to 3 are reported, as no rejections of the null were detected for $d>3$.

\section{TABLE 5}

\section{TABLE 6}

Table 5 presents the results from the application of a TAR model to the annual data on the Italian regions over the years 1978-2003, while the M-TAR estimates are reported in Table 6. Overall, the tests provide evidence of a significant threshold effect for 8 out of the 20 Italian regions' output growth rates, with Liguria being the only case in which both the TAR and M-TAR models indicate the presence of a threshold and a few other instances in which the tests reject the null of no threshold with more than one threshold variable ${ }^{19}$.

With respect to that obtained using the LLT procedure, these results paint a more variegate picture as regards the hypothesis of a non-linear nature of growth for the regions of

\footnotetext{
${ }^{18}$ We are aware of the fact that using the growth rate of output, as opposed to its log-level, may be subject to critiques, as in so doing we lose some information. However, in keeping with LLT's analysis, this choice is dictated by our interest in the potential nonlinearity and endogeneity of the natural rate of growth.

19 Following Hansen (1997), in such cases the selection of the appropriate threshold estimate is determined by the smallest associated residual sum of squares.
} 
Italy, restricting its relevance to only 40 per cent of them. In three cases, i.e. Molise, Calabria and Sardegna, the threshold effect turns out to be triggered by a deceleration of growth, at various lag lengths, while the remaining regions are characterised by either a positive threshold rate of output growth or, in the case of Toscana, by a positive threshold $\Delta g_{t}$. This heterogeneity opens up different possible scenarios as regards the relative importance of the aforementioned mechanisms which can potentially spur endogenous growth. Further, it is interesting to note that 5 out of the 8 regions for which the tests indicate the presence of a significant threshold effect belong to the less-advanced Mezzogiorno, suggesting that the role of these factors may be more important in the latter.

To further investigate these issues, we now turn to the analysis of the impact of these threshold effects on the regional growth process in Italy. As usual, we rely on SUR methods to exploit cross-regional correlation in increasing the efficiency of the estimates but, because of the finding of a significant threshold for Calabria when $q_{t-1}=\Delta g_{t-2}$, the time-period under analysis is now restricted to the period 1982-2003. As only 14 per cent of the observations for Basilicata's output growth rate fall in the high-growth regime, the inclusion of this region in the model leads to collinearity problems, so that it is necessarily excluded from the sample. Further, the small region of Valle d'Aosta is also excluded as, due to the just-mentioned timeseries reduction, the SUR estimator is now only feasible with a cross-sectional dimension of 18 or less.

We carry out our investigation considering the following three models

$$
\begin{aligned}
& g_{t}=\alpha_{3}+\beta_{3}\left(\Delta \% U_{t}\right)+\lambda_{3} D+\theta_{3}\left(D \Delta \% U_{t}\right) \\
& g_{t}=\alpha_{7}+\delta_{7} g_{t-1}+\lambda_{7} D+\omega_{7} D g_{t-1} \\
& g_{t}=\alpha_{8}+\delta_{8} g_{t-1}+\beta_{8}\left(\Delta \% U_{t}\right)+\lambda_{8} D+\omega_{8} D g_{t-1}+\theta_{8}\left(D \Delta \% U_{t}\right)
\end{aligned}
$$

where

$$
D=\left\{\begin{array}{cc}
1 & q_{t-1}>\gamma \\
0 & \text { otherwise }
\end{array}\right.
$$


and the intercept and slope dummies are introduced only for the regions characterised by a significant threshold effect, to allow the relevant parameter changes between the low- and high-growth regimes.

Equation (3'), as shown in the previous section, reflects the ideas put forward by LLT, while equation (7) fits the TAR model in (5) or (6) to the growth rate of output $g_{t}$. Finally, nesting (3') and (7), equation (8) is the general model which takes account of both the relation between output growth and unemployment (following LLT) and the autoregressive dynamics of $g_{t}$ (building on the TAR approach). Thus, equations (3’) and (7) result from the imposition of exclusion restrictions on (8). As usual, we carry out formal tests on these and any possible cross-sectional restrictions to choose the best formulation for each of the three models and, subsequently, the model which fits the data best among the latter.

As it turns out, the LR test, the AIC and SBC indicate the common- $\beta_{8}$ equation (8) model as the most appropriate. This can be interpreted as a two-regime Okun's Law, allowing for some degree of persistence in output growth. The non-rejection of the common- $\beta_{8}$ restriction implies that there is no significant cross-regional heterogeneity in the sensitivity of unemployment to output growth when the latter is not in the high-growth state. From an econometric viewpoint, equation (8) is an Autoregressive Distributed Lag (ADL) model, or ADL $(1,1)$. The dynamic nature of the model allows one to distinguish the short-run relation between output growth and unemployment changes, which corresponds to Okun's Law, from the long-run equilibrium value of the rate of growth of output, which defines the natural rate of growth.

Specifically, the long-run equilibrium $g_{N}$ in the cases to which a linear relationship applies is given by

$$
g_{N}=\left(\frac{\alpha_{8}}{1-\delta_{8}}\right)
$$

Equation (10) also specifies the natural rate of output for the low-growth regime of the 7 regions to which, because of significant threshold effects, a non-linear relation is fitted. In such instances, the high-growth regime $g_{N}$ is given by 
$g_{N}=\left(\frac{\alpha_{8}+\lambda_{8}}{1-\delta_{8}-\omega_{8}}\right)$

Both expressions show that the natural rate of growth will be dependent on the degree of persistence in output growth. More specifically, the expression in (11) illustrates that the switch from one growth regime to the other will affect $g_{N}$ not only, as in the LLT approach, through the intercept shift in the relation (given by $\lambda_{8}$ ), but also via the change in the degree of persistence in output growth, determined by the size and sign of the $\omega_{8}$ coefficient.

The estimation results are reported in Table 7 and, as for the outcome of the threshold tests, they provide a fairly heterogeneous account of the features of regional growth in Italy. The common $\beta_{8}$ coefficient is strongly significant and, as expected takes on a negative sign. This confirms the countercyclical pattern of unemployment in the absence of non-linearities in the relation with output growth, as well as in the low-growth regime of the 7 cases in which this relation is non-linear. The coefficient on the $D \Delta \% U_{t}$ slope dummy variable turns out to be positive in 6 out of 7 cases, in 5 significantly so. This results in a significantly positive slope coefficient in the high-growth regime in 3 cases, while the same parameter is significantly negative only in one instance (i.e. Liguria) and not significant in the remaining three cases. Though not conclusive, overall this evidence reinforces the view that, when considered in a non-linear framework and within the context of a high-growth regime, a procyclical evolution of unemployment is a concrete possibility, rather than a mere theoretical nuisance.

\section{TABLE 7}

Turning to the assessment of LLT's endogeneity hypothesis, one can start by observing that the estimates for Friuli Venezia Giulia, Toscana and Sardegna fit the broad picture given by the results in Section 3. The natural rate of growth rises when growth or its acceleration rate are higher than the relevant estimated threshold values, though only marginally in the case of Sardegna. Moreover, from countercyclical, unemployment becomes pro-cyclical or, in the case of Toscana, acyclical in the high-growth regime. These results suggest that both productivity and labour force participation are positively related to output growth, bringing support to the LLT approach. 
Liguria and Sicilia, on the contrary, are characterised by a fall in $g_{N}$ in the high-growth scenario, brought about, respectively, by a negative and an insignificant coefficient on the intercept dummy variable $D$. Thus, the theories positing a positive effect of recessions or slow growth on productivity growth, as reviewed by Saint-Paul (1997), seem to provide a better theoretical background for the endogenous pattern of these two regions' growth process.

As regards both Molise and Calabria, taken at face value, the results seem highly implausible and present interpretation problems. This is likely to depend on the uneven distribution of the observations between the two growth regimes, as only 24 percent of them fall in the slow-growth case for Calabria and just 29 percent for Molise.

Despite these problems, however, the empirical evidence gathered in this section appears fairly robust and does provide a number of valuable insights, in particular when compared to and complemented by the results coming from the implementation of the LLT approach.

Firstly, if the LLT theoretical structure is not imposed a priori, the data reject the hypothesis of a non-linear regional growth process for 12 out of the 20 Italian regions. Contrary to the results in Section 3, this evidence runs against the view that growth endogeneity, at least as defined by LLT and in this paper, is the general principle determining the economic performance of the Italian regions.

Secondly, when growth does appear to be endogenous, the data provide contrasting evidence as regards the relation between the actual and the natural growth rates. This suggests that both the mechanisms pointed at by LLT, as well as the literature on endogenous business cycles, and the forces which can potentially determine a countercyclical pattern of productivity growth can play a significant role in the growth process. Further, it reinforces the view that the actual sign of the relation can only be ascertained empirically.

Finally, the results in this section confirm that, when growth is non-linear, significant asymmetries seem to appear also in the cyclical pattern of unemployment which, with the switch from a low- to a high-growth regime, can turn from countercyclical to acyclical or procyclical. 


\section{Conclusions}

Taking as a starting point their diverse performance over the nearly three decades covering the period 1977-2003, this paper investigates to what extent and in what sense the Italian regions' growth process can be defined as endogenous.

We start our analysis by following León-Ledesma and Thirlwall (2002a) in estimating the natural rate of output growth for each one of the Italian regions and, then, assessing its dependence from the actual growth rate. Both the LSDV and SUR regressions carried out in Section 3 bring support to LLT's endogeneity hypothesis, indicating the natural rate raises by about 3-3.7 percentage points when $g_{t}>g_{N}$.

Allowing for complete parameter flexibility, the SUR estimates also point to the existence of non-linearities in Okun's Law. Though this result is consistent with what has been recently suggested in the literature, the asymmetric Okun coefficient in the high-growth regime turns out to be positive in several cases, implying unemployment turns pro-cyclical when growth rises above a certain threshold rate. We provide an interpretation of this result relying on the insights provided by models of equilibrium unemployment with endogenous labour force participation which, under certain conditions, predict a pro-cyclical unemployment rate. Further, we argue that these conditions (e.g. wage flexibility, a higher elasticity of labour supply) are more likely to be met in a high-growth scenario and that this reinforces the need to investigate the potential non-linear nature and endogeneity of growth.

Thus, in the last part of the paper we proceed to complementing the analysis carried out via the LLT procedure implementing a purely data-driven approach. Following Hansen (1997), we find evidence of significant non-linearities in output growth for 8 Italian regions and then use the estimated thresholds to further investigate their implications for the endogeneity hypothesis and the cyclical pattern of unemployment. As regards the latter issue, the results are again consistent with the existence of an asymmetric Okun coefficient between growth regimes, with unemployment switching from a counter- to a pro-cyclical (or acyclical) pattern in booms. LLT's conjecture as regards the positive link between current and longgrowth growth, however, is not fully supported by the data, as we also find evidence of a higher natural rate when growth is slow in the case of two regions.

In conclusion, at a theoretical level the work carried out in this paper reinforces the view, championed by LLT, that under certain conditions the natural rate of output growth is endogenous, in the sense that it is partly dependent on actual short-run growth. At the same 
time, our results show that one should be cautious in drawing conclusions as regards the nature and sign of this relation, as abandoning the theory-based estimation procedure proposed by LLT for a purely data-driven approach is likely to provide a more complex picture.

From an economic policy point of view, the lesson is that both the mechanisms working pro-cyclically in raising the natural rate and those which come into play countercyclically can be effective. Thus, both short-term demand management and institutional changes facilitating the reallocation of resources towards productivity-enhancing activities in periods of recession or slow growth can potentially improve an economy's long-term prospects. Seen in these terms, the economic policy question seems to be not whether to intervene, but how much and how.

These remarks find their foundation in our analysis of the Italian regions and are, thus, particularly relevant in such a context. Regional growth in Italy appears as a largely heterogeneous phenomenon, suggesting that the reduction of the growth differentials mentioned in the introduction to this paper should be tackled via region-specific policies. Our results indicate that such intervention is likely to be particularly effective in the poorer southern regions, where the evidence supporting the endogeneity of growth is more robust. 


\section{Bibliography}

Attfield, C. and Silverstone, B. (1997) - “Okun’s Law, Cointegration and Gap Variables”, Journal of Macroeconomics, 20, 125-137

Andrews, D. W. K. (1993) - “Tests for Parameter Instability and Structural Change with Unknown Change Point”, Econometrica, 61, 821-856

Arrow, J. K. (1962) - “The Economic Implications of Learning-by-Doing”, Review of Economic Studies, 29, 155-173

Boggio, L. and Seravalli, G. (2002) - "Is the Natural Rate of Growth Exogenous? A Comment”, Banca Nazionale del Lavoro Quarterly Review, 221, 219-227.

Barro, R. J. (1991) - “Economic Growth in a Cross Section of Countries”, Quarterly Journal of Economics, 106, 407-443.

Blanchard, O. J. and Quah, D. (1989) - “The Dynamic Effects of Aggregate Demand and Supply Disturbances”, American Economic Review

Blackburn, K. (1999) - “Can Stabilisation Policies Reduce Long-Run Growth?”, The Economic Journal, 109, 67-77

Caballero, R. and Hammour, M. (1994) - “The Cleansing Effects of Recessions”, American Economic Review, 84, 1350-1368

Chan, K. S. (1993) - "Consistency and Limiting Distribution of the Least Squares Estimator of a Threshold Autoregressive Model”, The Annals of Statistics, 21, 520-533

Crespo Cuaresma, J. (2003) - “Okun’s Law Revisited”, Oxford Bulletin of Economics and Statistics, 65, 439-451.

Dixon, R. J. and Thirlwall, A. P. (1975) - "A Model of Regional Growth Rate Differences on Kaldorian Lines”, Oxford Economic Papers, 27, 201-213

Dustmann (1996) - "Return Migration: The European Experience”, Economic Policy, 22, 215--250

Dustmann, C. (2003) - "Return Migration and the Optimal Migration Duration” European Economic Review 2003, 47, 353-367

Enders, W. and Granger, C. W. J. (1998) - "Unit Root Tests and Asymmetric Adjustment with an Example Using the Term Structure of Interest Rates”, Journal of Business and Economic Statistics, 16, 304-311

Fatás, A. (2000) - “Endogenous Growth and Stochastic Trends”, Journal of Monetary Economics, 45, 107-128 
Grossman, G. M. and Helpman, E. (1991) - Innovation and Growth in the Global Economy, Cambridge: MIT Press

Haefke, C. and Reiter, M. (2006) - "Endogenous Labor Market Participation and the Business Cycle”, IZA Discussion Paper No. 2029

Hansen, B. E. (1996) - "Inference when a Nuisance Parameter is not Identified Under the Null Hypothesis”, Econometrica, 64, 413-430.

Hansen, B. E. (1997) - "Inference in TAR models", Studies in Nonlinear Dynamics and Econometrics, 2, 1-14.

Hansen, B. E. (1999) - “Threshold Effects in Non-Dynamic Panels: Estimation, Testing and Inference”, Journal of Econometrics, 93, 345-368

Hansen, B. E. (2000) - "Sample Splitting and Threshold Estimation”, Econometrica, 68, 575603.

Harrod, R. F. (1939) - “An Essay in Dynamic Theory”, Economic Journal, 49, 14-33

Harvey, A. C. (1985) - “Trends and Cycles in Macroeconomic Time Series”, Journal of Business and Economic Statistics, 13, 216-227

Harvey, A. C. (1989) - Forecasting: Structural Time Series Models and the Kalman Filter, Cambridge: Cambridge University Press

Hatton, T. J. and Williamson, J. G. (1998) - The Age of Mass Migration: Causes and Economic Impact, New York: Oxford University Press

Hatton, T. J. and Williamson, J. G. (2002) - “What Fundamentals Drive World Migration?”, NBER Working Paper Series, Working Paper 9159

Kaldor, N. (1966) - Causes of the Slow Rate of Growth of the United Kingdom, Cambridge: Cambridge University Press

Keynes, J. M. (1937) - “Some Economic Consequences of a Declining Population”, Eugenics Review, April

Lee, J. (2000) - “The Robustness of Okun’s Law: Evidence from OECD Countries”, Journal of Macroeconomics, 22, 331-356

León-Ledesma, M. A. (2002) - “Accumulation, Innovation and Catching-up: an Extended Cumulative Growth Model." Cambridge Journal of Economics, 2002, 26, 201-216

León-Ledesma, M. A. and Thirlwall, A. P. (2000) - "Il Tasso Naturale di Crescita é Davvero Esogeno?”, Moneta e Credito, 211, 263-277.

León-Ledesma, M. A. and Thirlwall, A. P. (2002a) - “The Endogeneity of the Natural Rate of Growth”, Cambridge Journal of Economics, 26, 441-459. 
León-Ledesma, M. A. and Thirlwall, A. P. (2002b) - "Is the Natural Rate of Growth Exogenous? A Reply”, Banca Nazionale del Lavoro Quarterly Review, 221, 229-232.

Lucas, R. E. (1988) - “On the Mechanics of Economic Development”, Journal of Monetary Economics, 22, 3-42

Massey, D. S., Arrango, J., Hugo, G., Kouaouci, A. Pellegrino, A. and Taylor, J. E. (1993) “Theories of International Migration: A Review and Appraisal”, Population and Development Review, 19, 431-466.

Okun, A. M. (1962) - "Potential GNP: Its Measurement and Significance”, in Proceedings of the Businness and Economic Statistics Section of the American Statistical Association, 7, 89-104

Perron, P. (1997) - "Further Evidence on Breaking Trend Functions in Macroeconomic Variables”, Journal of Econometrics, 80, 355-385.

Romer, P. M. (1986) - “Increasing Returns and Long Run Growth”, Journal of Political Economy, 94, 1002-1037

Romer, P. M. (1990) - “Endogenous Technological Change”, Journal of Political Economy, 98, 71-102

Saint-Paul, G. (1997) - "Business Cycles and Long-Run Growth”, Oxford Review of Economic Policy, 13, 145-153

Silvapulle, P., Moosa, I. A. and Silvapulle, M. J. (2004) - “Asymmetry in Okun’s Law”, Canadian Journal of Economics, 37, 353-374

Stadler, G. W. (1990) - "Business Cycle Models with Endogenous Technology”, American Economic Review, 80, 763-778

Schumpeter, J. A. (1939) - Business Cycles, McGraw-Hill, New York

Schumpeter, J. A. (1950) - Capitalism, Socialism and Democracy, Harper and Row, New York

Shimer (2004) - "Search Intensity”, University of Chicago, Mimeo

Thirlwall, A. P. (1969) - “Okun's Law and the Natural Rate of Growth”, The Southern Economic Journal, 36, 87-89

Tripier, F. (2002) - "Can the Labor Market Search Model Explain the Fluctuations of Allocations of Time?”, Economic Modelling, 21, 131-146

Veracierto, M. (2004) - “On the Cyclical Behaviour of Employment, Unemployment and Labor Force Participation”, Federal Reserve Bank of Chicago, WP 2002-12

Verdoorn, P. J. (1949) - "Fattori che Regolano lo Sviluppo della Produttività del Lavoro", L'Industria, 1, 45-53 
Viren, M. (2001) - “The Okun Curve is Non-Linear”, Economics Letters, 70, 253-257

Young, A. (1928) - “Increasing Returns and Economic Progress”, Economic Journal, 38, $527-542$ 
Table 1. LSDV estimations

\begin{tabular}{|c|c|c|c|c|c|c|}
\hline & \multicolumn{3}{|c|}{ Okun’s Law } & \multicolumn{3}{|c|}{ Thirlwall’s reversal } \\
\hline \multirow[b]{2}{*}{ Region } & \multirow{2}{*}{$\begin{array}{l}\text { Equation (1) } \\
\qquad g_{N}\end{array}$} & \multicolumn{2}{|c|}{ Equation (3) } & \multirow{2}{*}{$\begin{array}{l}\text { Equation (2) } \\
\qquad g_{N}\end{array}$} & \multicolumn{2}{|c|}{ Equation (3) } \\
\hline & & $\alpha_{3}$ & $\begin{array}{c}\text { Boom } \\
g_{N}\end{array}$ & & $\alpha_{3}$ & $\begin{array}{c}\text { Boom } \\
g_{N}\end{array}$ \\
\hline Piemonte & 2.812 & $1.317 \wedge$ & $4.309 \wedge$ & $3.161^{\wedge}$ & $1.159 \wedge$ & 4.532 \\
\hline Valle d'Aosta & 3.128 & $1.573^{\wedge}$ & $4.565^{\wedge}$ & $3.076^{\wedge}$ & $1.329 \wedge$ & 4.703 \\
\hline Lombardia & 3.307 & $1.970^{\wedge}$ & $4.963 \wedge$ & $3.586^{\wedge}$ & $1.842^{\wedge}$ & 5.215 \\
\hline $\begin{array}{l}\text { Trentino Alto } \\
\text { Adige }\end{array}$ & 3.408 & $2.266^{\wedge}$ & $5.259 \wedge$ & $3.994 \wedge$ & $1.993^{\wedge}$ & 5.367 \\
\hline Veneto & 3.281 & $2.219^{\wedge}$ & $5.212^{\wedge}$ & $4.062^{\wedge}$ & $2.321^{\wedge}$ & 5.695 \\
\hline $\begin{array}{c}\text { Friuli Venezia } \\
\text { Giulia }\end{array}$ & 2.493 & $2.081^{\wedge}$ & $5.073^{\wedge}$ & $3.811^{\wedge}$ & $1.808^{\wedge}$ & 5.182 \\
\hline Liguria & 2.738 & $1.522^{\wedge}$ & $4.514^{\wedge}$ & $3.248^{\wedge}$ & $1.249^{\wedge}$ & 4.623 \\
\hline $\begin{array}{l}\text { Emilia } \\
\text { Romagna }\end{array}$ & 2.915 & $1.991^{\wedge}$ & $4.983^{\wedge}$ & $3.714^{\wedge}$ & $1.718^{\wedge}$ & 5.092 \\
\hline Toscana & 2.288 & $1.931^{\wedge}$ & $4.923^{\wedge}$ & $3.431^{\wedge}$ & $1.817^{\wedge}$ & 5.191 \\
\hline Umbria & 2.805 & $1.578^{\wedge}$ & $4.570^{\wedge}$ & $3.754 \wedge$ & $2.025^{\wedge}$ & 5.399 \\
\hline Marche & 3.150 & $1.681^{\wedge}$ & $4.673^{\wedge}$ & $3.523^{\wedge}$ & $1.782^{\wedge}$ & 5.156 \\
\hline Lazio & 2.466 & $2.065^{\wedge}$ & $5.058 \wedge$ & $3.794 \wedge$ & $2.052^{\wedge}$ & 5.426 \\
\hline Abruzzo & 5.489 & $1.943^{\wedge}$ & $4.936^{\wedge}$ & $3.890 \wedge$ & $2.031^{\wedge}$ & 5.405 \\
\hline Molise & $7.026^{\wedge}$ & $2.743^{\wedge}$ & $5.736^{\wedge}$ & $4.042^{\wedge}$ & $2.268^{\wedge}$ & 5.642 \\
\hline Campania & $5.391 \wedge$ & $2.779 \wedge$ & $5.771^{\wedge}$ & $3.647 \wedge$ & $1.712^{\wedge}$ & 5.086 \\
\hline Puglia & $5.236 *$ & $2.631^{\wedge}$ & $5.623^{\wedge}$ & $3.590^{\wedge}$ & $1.680^{\wedge}$ & 5.054 \\
\hline Basilicata & $6.893^{*}$ & $2.331^{\wedge}$ & $5.323 \wedge$ & $3.406^{\wedge}$ & $1.106^{\wedge}$ & 4.480 \\
\hline Calabria & $6.799 \wedge$ & $2.368^{\wedge}$ & $5.360^{\wedge}$ & $3.466^{\wedge}$ & $1.531^{\wedge}$ & 4.905 \\
\hline Sicilia & $4.918 \wedge$ & $2.636^{\wedge}$ & $5.628 \wedge$ & $3.616^{\wedge}$ & $1.943^{\wedge}$ & 5.317 \\
\hline Sardegna & $2.812^{*}$ & $2.438^{\wedge}$ & $5.430^{\wedge}$ & $3.279 \wedge$ & $1.501^{\wedge}$ & 4.875 \\
\hline Average & 3.957 & 2.103 & 5.095 & 3.604 & 1.743 & 5.117 \\
\hline$\lambda_{3}$ & \multicolumn{4}{|c|}{$2.992^{\wedge}$} & \multicolumn{2}{|c|}{$3.374 \wedge$} \\
\hline$\beta$ & $-0.106^{\wedge}$ & \multicolumn{2}{|c|}{$-0.189 *$} & $-0.325^{\wedge}$ & \multicolumn{2}{|c|}{$-0.181 *$} \\
\hline$R^{2}$ & 0.440 & \multicolumn{2}{|c|}{0.596} & 0.403 & \multicolumn{2}{|c|}{0.653} \\
\hline Wald test & $8.019 \wedge$ & \multicolumn{2}{|c|}{$117.9^{\wedge}$} & $15.01^{\wedge}$ & \multicolumn{2}{|c|}{$172.9^{\wedge}$} \\
\hline AR1 test & -0.720 & \multicolumn{2}{|c|}{-1.074} & -1.116 & \multicolumn{2}{|c|}{-1.520} \\
\hline AR2 test & $-2.218 *$ & \multicolumn{2}{|c|}{0.001} & 0.517 & \multicolumn{2}{|c|}{-0.007} \\
\hline
\end{tabular}

Notes:

The Wald test for the joint significance of the variables is distributed as a chi-squared with two degrees of freedom;

The AR1 and AR2 tests are the autocorrelation tests routinely reported by PC-Give 10.0. These are based on the standardized average residual autocovariances, which are asymptotically $\mathrm{N}(0,1)$ variables under the null of no autocorrelation. The tests reported are based on estimates of the residuals in first differences;

$\wedge$ and * indicate, respectively, significant at the $1 \%$ and $5 \%$ level of significance. 
Table 2. Okun's Law approach, SUR estimations

\begin{tabular}{|c|c|c|c|c|c|c|c|c|}
\hline \multicolumn{9}{|c|}{ Equation (1) } \\
\hline All regions & & & $\begin{array}{c}g_{N} \\
3.036^{\wedge}\end{array}$ & $\begin{array}{c}\beta_{2} \\
-0.049 \wedge\end{array}$ & $\begin{array}{c}\bar{R}^{2} \\
0.818\end{array}$ & & & \\
\hline \multicolumn{9}{|c|}{ Equation (3’) } \\
\hline Region & $\alpha_{3}$ & $\beta_{3}$ & $\lambda_{3}$ & $\theta_{3}$ & $\begin{array}{c}\text { Boom } \\
g_{N}\end{array}$ & $\left(\beta_{3}+\theta_{3}\right)$ & $\bar{R}^{2}$ & DW \\
\hline Piemonte & $0.805^{\wedge}$ & $-0.353^{\wedge}$ & $3.703^{\wedge}$ & 0.326 & $4.508^{\wedge}$ & -0.027 & 0.544 & 1.687 \\
\hline Valle d'Aosta & $0.919 \wedge$ & -0.090 & $3.703^{\wedge}$ & $-0.310 * *$ & $4.622^{\wedge}$ & $-0.400 *$ & 0.538 & 1.229 \\
\hline Lombardia & $1.111^{\wedge}$ & $-0.450^{\wedge}$ & $3.703^{\wedge}$ & $0.867 \wedge$ & $4.814^{\wedge}$ & $0.417 * *$ & 0.599 & 1.551 \\
\hline $\begin{array}{l}\text { Trentino Alto } \\
\text { Adige }\end{array}$ & $1.480^{\wedge}$ & $-0.214^{\wedge}$ & $3.703^{\wedge}$ & $1.241^{\wedge}$ & $5.183^{\wedge}$ & $1.027 \wedge$ & 0.600 & 1.980 \\
\hline Veneto & $1.104^{\wedge}$ & $0.152 * *$ & $3.703^{\wedge}$ & $0.289 *$ & $4.807 \wedge$ & $0.441^{\wedge}$ & 0.589 & 1.810 \\
\hline $\begin{array}{l}\text { Friuli Venezia } \\
\text { Giulia }\end{array}$ & $1.262^{\wedge}$ & $-0.640^{\wedge}$ & $3.703^{\wedge}$ & $1.299 \wedge$ & $4.965^{\wedge}$ & $0.659 \wedge$ & 0.674 & 2.495 \\
\hline Liguria & $0.959 *$ & $-0.579 \wedge$ & $3.703^{\wedge}$ & $1.087 \wedge$ & $4.662^{\wedge}$ & $0.508 \wedge$ & 0.483 & 2.176 \\
\hline $\begin{array}{l}\text { Emilia } \\
\text { Romagna }\end{array}$ & $1.098 \wedge$ & $-0.574 \wedge$ & $3.703^{\wedge}$ & $0.589 \wedge$ & $4.801^{\wedge}$ & 0.015 & 0.749 & 1.978 \\
\hline Toscana & $1.121^{\wedge}$ & $-0.771^{\wedge}$ & $3.703^{\wedge}$ & $1.286^{\wedge}$ & $4.824 \wedge$ & $0.515 * *$ & 0.590 & 1.690 \\
\hline Umbria & $1.121^{\wedge}$ & $-0.179 \wedge$ & $3.703^{\wedge}$ & $-0.193 *$ & $4.824 \wedge$ & $-0.372^{\wedge}$ & 0.367 & 1.981 \\
\hline Marche & $0.918^{\wedge}$ & 0.042 & $3.703^{\wedge}$ & $-0.824 \wedge$ & $4.621^{\wedge}$ & $-0.782^{\wedge}$ & 0.553 & 2.255 \\
\hline Lazio & $1.302^{\wedge}$ & -0.037 & $3.703^{\wedge}$ & $1.677 \wedge$ & $5.005^{\wedge}$ & $1.640^{\wedge}$ & 0.604 & 1.602 \\
\hline Abruzzo & $1.406^{\wedge}$ & -0.225 & $3.703^{\wedge}$ & 0.238 & $5.109 \wedge$ & 0.013 & 0.724 & 1.899 \\
\hline Molise & $1.371^{\wedge}$ & -0.073 & $3.703^{\wedge}$ & 0.152 & $5.074 \wedge$ & 0.079 & 0.412 & 1.818 \\
\hline Campania & $1.184^{\wedge}$ & $-0.144^{\wedge}$ & $3.703^{\wedge}$ & $0.293^{\wedge}$ & $4.887 \wedge$ & $0.149 *$ & 0.579 & 1.872 \\
\hline Puglia & $1.015^{\wedge}$ & 0.001 & $3.703^{\wedge}$ & $-0.341 *$ & $4.718^{\wedge}$ & $-0.340^{*}$ & 0.625 & 1.661 \\
\hline Basilicata & 0.659* & $-0.616^{\wedge}$ & $3.703^{\wedge}$ & 0.165 & $4.362^{\wedge}$ & $-0.451^{\wedge}$ & 0.686 & 1.600 \\
\hline Calabria & 0.433 & 0.089 & $3.703^{\wedge}$ & -0.050 & $4.136^{\wedge}$ & 0.039 & 0.517 & 2.290 \\
\hline Sicilia & $1.372^{\wedge}$ & $-0.181^{\wedge}$ & $3.703^{\wedge}$ & $0.471^{\wedge}$ & $5.075^{\wedge}$ & $0.290^{\wedge}$ & 0.568 & 2.432 \\
\hline Sardegna & $0.817^{\wedge}$ & $-0.218^{\wedge}$ & $3.703^{\wedge}$ & -0.070 & $4.520^{\wedge}$ & $-0.288^{\wedge}$ & 0.553 & 1.812 \\
\hline Average & 1.073 & -0.253 & 3.703 & 0.410 & 4.776 & 0.157 & 0.578 & 1.891 \\
\hline
\end{tabular}

Notes:

The reported $\bar{R}^{2}$ for Equation (5.1) is the simple average of the $\bar{R}^{2}$ values for the 20 regional regressions;

$\wedge$, * and ** indicate, respectively, significant at the $1 \%, 5 \%$ and $10 \%$ level of significance. 
Table 3. Thirlwall's reversal approach, SUR estimations

\begin{tabular}{|c|c|c|c|c|}
\hline \multirow[b]{2}{*}{ Region } & \multicolumn{4}{|c|}{ Equation (2) } \\
\hline & $g_{N}$ & $\beta_{2}$ & $\bar{R}^{2}$ & DW \\
\hline Piemonte & $1.732^{\wedge}$ & $-0.600^{\wedge}$ & 0.817 & 1.412 \\
\hline $\begin{array}{l}\text { Valle } \\
\text { d'Aosta }\end{array}$ & $1.547 \wedge$ & $-0.643 \wedge$ & 0.793 & 2.053 \\
\hline Lombardia & $2.119 \wedge$ & $-1.012^{\wedge}$ & 0.849 & 1.303 \\
\hline $\begin{array}{l}\text { Trentino Alto } \\
\text { Adige }\end{array}$ & $2.641^{\wedge}$ & $-0.784^{\wedge}$ & 0.778 & 1.814 \\
\hline Veneto & $2.646^{\wedge}$ & $-0.427 \wedge$ & 0.767 & 1.352 \\
\hline $\begin{array}{l}\text { Friuli Venezia } \\
\text { Giulia }\end{array}$ & $2.362^{\wedge}$ & $-0.827 \wedge$ & 0.778 & 1.678 \\
\hline Liguria & $1.865^{\wedge}$ & $-0.314^{*}$ & 0.784 & 1.722 \\
\hline Emilia & $2.271^{\wedge}$ & $-0.828 \wedge$ & 0.785 & 1.150 \\
\hline Romagna & & & & \\
\hline Toscana & $1.884^{\wedge}$ & -0.090 & 0.786 & 1.454 \\
\hline Umbria & $2.384^{\wedge}$ & $-0.698 \wedge$ & 0.785 & 1.939 \\
\hline Marche & $2.073^{\wedge}$ & $0.324^{*}$ & 0.779 & 1.382 \\
\hline Lazio & $2.424 \wedge$ & $-0.584 \wedge$ & 0.820 & 1.564 \\
\hline Abruzzo & $2.648^{\wedge}$ & -0.014 & 0.825 & 1.034 \\
\hline Molise & $2.592^{\wedge}$ & 0.012 & 0.774 & 1.664 \\
\hline Campania & $2.257 \wedge$ & $-0.322^{\wedge}$ & 0.800 & 1.763 \\
\hline Puglia & $2.199 \wedge$ & -0.016 & 0.806 & 1.282 \\
\hline Basilicata & $2.440^{\wedge}$ & $-0.709 \wedge$ & 0.814 & 1.507 \\
\hline Calabria & $1.296 *$ & $0.421^{\wedge}$ & 0.792 & 3.438 \\
\hline Sicilia & $2.405^{\wedge}$ & $-0.370^{\wedge}$ & 0.802 & 1.123 \\
\hline Sardegna & $1.809 \wedge$ & -0.028 & 0.774 & 2.116 \\
\hline Average & 2.180 & -0.375 & 0.795 & \\
\hline
\end{tabular}


Table 4. Thirlwall's reversal approach, SUR estimations

\begin{tabular}{|c|c|c|c|c|c|c|c|c|}
\hline \multicolumn{9}{|c|}{ Equation (3’) } \\
\hline Region & $\alpha_{3}$ & $\beta_{3}$ & $\lambda_{3}$ & $\theta_{3}$ & $\begin{array}{c}\text { Boom } \\
g_{N}\end{array}$ & $\left(\beta_{3}+\theta_{3}\right)$ & $\bar{R}^{2}$ & DW \\
\hline Piemonte & 0.209 & $-0.229 *$ & $2.619 \wedge$ & $0.216^{\wedge}$ & $2.828^{\wedge}$ & -0.013 & 0.709 & 2.011 \\
\hline Valle d'Aosta & 0.289 & -0.029 & $3.490^{\wedge}$ & $0.216^{\wedge}$ & $3.779 \wedge$ & 0.187 & 0.411 & 2.266 \\
\hline Lombardia & $1.168^{\wedge}$ & $-0.417 \wedge$ & $2.115^{\wedge}$ & $0.216^{\wedge}$ & $3.283^{\wedge}$ & $-0.201^{*}$ & 0.730 & 1.952 \\
\hline $\begin{array}{l}\text { Trentino Alto } \\
\text { Adige }\end{array}$ & $0.780 *$ & $0.451^{\wedge}$ & $4.770^{\wedge}$ & $0.216^{\wedge}$ & $5.550^{\wedge}$ & $0.667 \wedge$ & 0.625 & 2.008 \\
\hline Veneto & $1.173^{\wedge}$ & -0.045 & $3.204^{\wedge}$ & $0.216^{\wedge}$ & $4.377 \wedge$ & $0.171^{*}$ & 0.608 & 1.861 \\
\hline $\begin{array}{l}\text { Friuli Venezia } \\
\text { Giulia }\end{array}$ & $0.815^{\wedge}$ & $-0.289 \wedge$ & $3.797 \wedge$ & $0.216^{\wedge}$ & $4.612^{\wedge}$ & -0.073 & 0.618 & 1.961 \\
\hline Liguria & 0.357 & 0.051 & $3.610^{\wedge}$ & $0.216^{\wedge}$ & $3.967 \wedge$ & $0.267 * *$ & 0.404 & 2.084 \\
\hline Emilia & $0.991^{\wedge}$ & $-0.684 \wedge$ & $3.461^{\wedge}$ & $0.216^{\wedge}$ & $4.452^{\wedge}$ & $-0.468 \wedge$ & 0.770 & 1.198 \\
\hline Romagna & & & & & & & & \\
\hline Toscana & $0.894^{\wedge}$ & -0.171 & $2.657 \wedge$ & $0.216^{\wedge}$ & $3.551^{\wedge}$ & 0.045 & 0.563 & 1.810 \\
\hline Umbria & 0.403 & $-1.147 \wedge$ & $3.956^{\wedge}$ & $0.216^{\wedge}$ & $4.359 \wedge$ & $-0.931^{\wedge}$ & 0.481 & 1.858 \\
\hline Marche & $0.559 *$ & -0.209 & $3.043^{\wedge}$ & $0.216^{\wedge}$ & $3.602^{\wedge}$ & 0.007 & 0.639 & 2.110 \\
\hline Lazio & $1.257 \wedge$ & $0.130^{\wedge}$ & $2.545^{\wedge}$ & $0.216^{\wedge}$ & $3.802^{\wedge}$ & $0.346^{\wedge}$ & 0.757 & 1.667 \\
\hline Abruzzo & $1.466^{\wedge}$ & 0.078 & $3.206^{\wedge}$ & $0.216^{\wedge}$ & $4.672^{\wedge}$ & $0.294^{\wedge}$ & 0.717 & 1.351 \\
\hline Molise & $0.779 * *$ & $-0.093 *$ & $4.876^{\wedge}$ & $0.216^{\wedge}$ & $5.655^{\wedge}$ & $0.123 *$ & 0.446 & 2.014 \\
\hline Campania & $0.653^{\wedge}$ & 0.093 & $2.884^{\wedge}$ & $0.216^{\wedge}$ & $3.537 \wedge$ & $0.309 \wedge$ & 0.688 & 2.724 \\
\hline Puglia & $0.619 \wedge$ & $-0.368 \wedge$ & $3.325^{\wedge}$ & $0.216^{\wedge}$ & $3.944 \wedge$ & $-0.152^{\wedge}$ & 0.726 & 1.941 \\
\hline Basilicata & 0.257 & $-0.722^{\wedge}$ & $4.294^{\wedge}$ & $0.216^{\wedge}$ & $4.551^{\wedge}$ & $-0.506^{\wedge}$ & 0.699 & 2.072 \\
\hline Calabria & $-0.698 *$ & $-0.157 \wedge$ & $4.151^{\wedge}$ & $0.216^{\wedge}$ & $3.453^{\wedge}$ & 0.059 & 0.561 & 2.064 \\
\hline Sicilia & $1.266^{\wedge}$ & $-0.272 *$ & $2.523^{\wedge}$ & $0.216^{\wedge}$ & $3.789 \wedge$ & -0.056 & 0.554 & 1.124 \\
\hline Sardegna & $0.760^{\wedge}$ & 0.013 & $2.425^{\wedge}$ & $0.216^{\wedge}$ & $3.185^{\wedge}$ & $0.229 \wedge$ & 0.638 & 1.728 \\
\hline Average & 0.700 & -0.201 & 3.348 & 0.216 & 4.047 & 0.015 & 0.617 & \\
\hline
\end{tabular}

Notes:

$\wedge, *$ and $* *$ indicate, respectively, significant at the $1 \%, 5 \%$ and $10 \%$ level of significance. 
Table 5. Hansen threshold test, TAR model

\begin{tabular}{|c|c|c|c|c|c|c|c|c|c|}
\hline \multirow[b]{2}{*}{ Region } & \multicolumn{3}{|c|}{$q_{t-1}=g_{t-1}$} & \multicolumn{3}{|c|}{$q_{t-1}=g_{t-2}$} & \multicolumn{3}{|c|}{$q_{t-1}=g_{t-3}$} \\
\hline & $\gamma$ & F-Test & $\mathrm{P}$-value & $\gamma$ & F-Test & P-value & $\gamma$ & F-Test & P-value \\
\hline Piemonte & 1.060 & 4.326 & 0.202 & 3.643 & 1.860 & 0.662 & -0.205 & 2.206 & 0.564 \\
\hline $\begin{array}{l}\text { Valle } \\
\text { d'Aosta }\end{array}$ & 0.442 & 2.188 & 0.615 & 0.129 & 4.003 & 0.203 & 0.129 & 4.820 & 0.128 \\
\hline Lombardia & 1.904 & 2.105 & 0.642 & 0.804 & 3.492 & 0.271 & 1.784 & 4.321 & 0.193 \\
\hline $\begin{array}{l}\text { Trentino Alto } \\
\text { Adige }\end{array}$ & 0.083 & 3.762 & 0.268 & 0.755 & 1.884 & 0.624 & 0.755 & 4.259 & 0.197 \\
\hline Veneto & 3.696 & 1.058 & 0.953 & 1.419 & 2.503 & 0.481 & 4.102 & 1.443 & 0.836 \\
\hline $\begin{array}{l}\text { Friuli Venezia } \\
\text { Giulia }\end{array}$ & 3.851 & 7.557 & 0.033 & 3.851 & 4.918 & 0.127 & 0.072 & 2.308 & 0.529 \\
\hline Liguria & -0.346 & 4.044 & 0.209 & 1.920 & 8.097 & 0.022 & 1.920 & 6.349 & 0.059 \\
\hline $\begin{array}{l}\text { Emilia } \\
\text { Romagna }\end{array}$ & 2.632 & 2.119 & 0.645 & 1.725 & 4.904 & 0.121 & 3.269 & 3.847 & 0.227 \\
\hline Toscana & 1.075 & 0.491 & 0.997 & 2.675 & 3.801 & 0.239 & 4.090 & 0.960 & 0.924 \\
\hline Umbria & 0.114 & 1.655 & 0.731 & 1.401 & 2.107 & 0.542 & 2.055 & 1.175 & 0.902 \\
\hline Marche & 1.722 & 2.114 & 0.647 & 0.410 & 3.238 & 0.292 & 1.654 & 2.359 & 0.467 \\
\hline Lazio & 1.487 & 2.895 & 0.450 & 1.152 & 2.328 & 0.581 & 3.428 & 3.417 & 0.303 \\
\hline Abruzzo & 2.592 & 1.438 & 0.814 & 2.314 & 0.877 & 0.935 & 1.811 & 1.062 & 0.888 \\
\hline Molise & 0.614 & 1.545 & 0.771 & 3.793 & 3.598 & 0.240 & 6.436 & 2.183 & 0.563 \\
\hline Campania & 0.138 & 1.970 & 0.721 & 1.771 & 2.051 & 0.621 & 3.703 & 2.870 & 0.391 \\
\hline Puglia & 1.150 & 1.682 & 0.768 & 1.238 & 1.608 & 0.765 & 2.167 & 1.397 & 0.807 \\
\hline Basilicata & 4.294 & 8.432 & 0.022 & 3.575 & 4.970 & 0.108 & -0.471 & 3.811 & 0.207 \\
\hline Calabria & 0.756 & 3.805 & 0.253 & 2.705 & 2.092 & 0.646 & 1.553 & 3.216 & 0.374 \\
\hline Sicilia & -0.098 & 5.223 & 0.115 & 2.023 & 7.705 & 0.026 & 2.511 & 2.094 & 0.552 \\
\hline Sardegna & 1.496 & 3.381 & 0.352 & 1.415 & 1.792 & 0.679 & 0.551 & 4.339 & 0.190 \\
\hline
\end{tabular}

Notes

The p-values are generated using 10000 bootstrap replications. 
Table 6. Hansen threshold test, MTAR model

\begin{tabular}{|c|c|c|c|c|c|c|c|c|c|}
\hline \multirow[b]{2}{*}{ Region } & \multicolumn{3}{|c|}{$q_{t-1}=\Delta g_{t}$} & \multicolumn{3}{|c|}{$q_{t-1}=\Delta g_{t-1}$} & \multicolumn{3}{|c|}{$q_{t-1}=\Delta g_{t-2}$} \\
\hline & $\gamma$ & F-Test & P-value & $\gamma$ & F-Test & P-value & $\gamma$ & F-Test & P-value \\
\hline Piemonte & 0.870 & 1.247 & 0.890 & 2.286 & 1.287 & 0.898 & -0.135 & 4.041 & 0.233 \\
\hline $\begin{array}{l}\text { Valle } \\
\text { d'Aosta }\end{array}$ & -0.693 & 1.067 & 0.930 & -0.522 & 4.589 & 0.148 & -0.244 & 2.275 & 0.573 \\
\hline Lombardia & -1.090 & 2.953 & 0.375 & -2.298 & 2.897 & 0.419 & 0.150 & 3.082 & 0.354 \\
\hline $\begin{array}{l}\text { Trentino Alto } \\
\text { Adige }\end{array}$ & 1.963 & 2.345 & 0.584 & 0.524 & 4.257 & 0.183 & -2.492 & 1.263 & 0.891 \\
\hline Veneto & 2.032 & 3.114 & 0.384 & -1.336 & 0.823 & 0.960 & 0.696 & 3.186 & 0.341 \\
\hline $\begin{array}{l}\text { Friuli Venezia } \\
\text { Giulia }\end{array}$ & -0.545 & 1.734 & 0.714 & -1.957 & 2.061 & 0.645 & 0.793 & 3.813 & 0.251 \\
\hline Liguria & 0.973 & 7.398 & 0.037 & -2.368 & 4.008 & 0.233 & -1.243 & 1.564 & 0.825 \\
\hline $\begin{array}{l}\text { Emilia } \\
\text { Romagna }\end{array}$ & -2.008 & 3.083 & 0.388 & -3.454 & 4.005 & 0.210 & 2.593 & 4.104 & 0.201 \\
\hline Toscana & 0.598 & 9.269 & 0.011 & 1.509 & 4.177 & 0.167 & 1.159 & 0.368 & 0.999 \\
\hline Umbria & -1.879 & 2.070 & 0.633 & 2.480 & 3.127 & 0.324 & 0.726 & 4.575 & 0.141 \\
\hline Marche & 0.662 & 3.519 & 0.291 & 0.660 & 1.387 & 0.826 & 2.785 & 3.256 & 0.327 \\
\hline Lazio & 0.307 & 1.310 & 0.852 & -1.583 & 4.878 & 0.137 & -1.456 & 1.843 & 0.690 \\
\hline Abruzzo & -0.646 & 1.619 & 0.706 & -0.182 & 0.882 & 0.937 & 1.210 & -1.069 & 0.842 \\
\hline Molise & -2.815 & 1.232 & 0.860 & -1.966 & 6.195 & 0.064 & -1.652 & 2.541 & 0.475 \\
\hline Campania & 2.119 & 3.534 & 0.299 & -1.320 & 3.707 & 0.294 & 0.141 & 1.150 & 0.899 \\
\hline Puglia & -0.710 & 1.553 & 0.762 & -1.852 & 1.368 & 0.801 & 0.420 & 1.988 & 0.617 \\
\hline Basilicata & 3.413 & 4.191 & 0.188 & 4.944 & 4.103 & 0.195 & 3.655 & 3.814 & 0.237 \\
\hline Calabria & -2.105 & 3.283 & 0.331 & -0.349 & 5.386 & 0.095 & -5.031 & 6.973 & 0.044 \\
\hline Sicilia & 1.688 & 2.666 & 0.508 & -0.897 & 2.245 & 0.609 & -1.794 & 3.391 & 0.317 \\
\hline Sardegna & -0.025 & 6.121 & 0.076 & 1.455 & 2.255 & 0.588 & -1.101 & 4.130 & 0.206 \\
\hline
\end{tabular}

Notes

The p-values are generated using 10000 bootstrap replications. 
Table 7. Common- $\beta_{8}$ equation (8) model, SUR estimation

\begin{tabular}{|c|c|c|c|c|c|c|c|c|c|c|c|}
\hline Region & $\alpha_{8}$ & $\delta_{8}$ & $\beta_{8}$ & $\lambda_{8}$ & $\omega_{8}$ & $\theta_{8}$ & Slow-growth $g_{N}$ & High-growth $g_{N}$ & $\left(\delta_{8}+\omega_{8}\right)$ & $\left(\beta_{8}+\theta_{8}\right)$ & $\bar{R}^{2}$ \\
\hline Piemonte & $1.666^{\wedge}$ & -0.007 & $-0.226 \wedge$ & - & - & - & $1.655^{\wedge}$ & $1.655^{\wedge}$ & - & - & 0.152 \\
\hline Valle d'Aosta & - & - & - & - & - & - & - & - & - & - & - \\
\hline Lombardia & $1.316^{\wedge}$ & $0.350^{\wedge}$ & $-0.226 \wedge$ & - & - & - & $2.026^{\wedge}$ & $2.026^{\wedge}$ & - & - & 0.365 \\
\hline $\begin{array}{l}\text { Trentino Alto } \\
\text { Adige }\end{array}$ & $2.744^{\wedge}$ & $-0.370^{\wedge}$ & $-0.226^{\wedge}$ & - & - & - & $2.003^{\wedge}$ & $2.003^{\wedge}$ & - & - & 0.070 \\
\hline Veneto & $2.016^{\wedge}$ & $0.101^{\wedge}$ & $-0.226^{\wedge}$ & - & - & - & $2.243^{\wedge}$ & $2.243^{\wedge}$ & - & - & -0.138 \\
\hline $\begin{array}{l}\text { Friuli Venezia } \\
\text { Giulia }\end{array}$ & $1.530^{\wedge}$ & $0.229 \wedge$ & $-0.226^{\wedge}$ & $15.254^{\wedge}$ & $-2.468 \wedge$ & $0.777^{\wedge}$ & $1.959 \wedge$ & $5.182^{\wedge}$ & $-2.239 \wedge$ & $0.551^{\wedge}$ & 0.315 \\
\hline Liguria & $1.942^{\wedge}$ & $0.117^{\wedge}$ & $-0.226^{\wedge}$ & $-1.003^{\wedge}$ & $-0.403^{\wedge}$ & $-1.014^{\wedge}$ & $2.200^{\wedge}$ & $0.731^{\wedge}$ & $-0.286^{\wedge}$ & $-1.241^{\wedge}$ & 0.533 \\
\hline $\begin{array}{l}\text { Emilia } \\
\text { Romagna }\end{array}$ & $1.702^{\wedge}$ & $0.193^{\wedge}$ & $-0.226^{\wedge}$ & - & - & - & $2.110^{\wedge}$ & $2.110^{\wedge}$ & - & - & -0.049 \\
\hline Toscana & $1.026^{\wedge}$ & $0.192^{\wedge}$ & $-0.226^{\wedge}$ & $4.608^{\wedge}$ & $-1.157 \wedge$ & 0.055 & $1.270^{\wedge}$ & $2.868^{\wedge}$ & $-0.965^{\wedge}$ & -0.171 & 0.383 \\
\hline Umbria & $1.656^{\wedge}$ & $0.073^{\wedge}$ & $-0.226^{\wedge}$ & - & - & - & $1.786^{\wedge}$ & $1.786^{\wedge}$ & - & - & -0.089 \\
\hline Marche & $2.155^{\wedge}$ & 0.046 & $-0.226^{\wedge}$ & - & - & - & $2.260^{\wedge}$ & $2.260^{\wedge}$ & - & - & -0.098 \\
\hline Lazio & $1.813^{\wedge}$ & $0.238^{\wedge}$ & $-0.226^{\wedge}$ & - & - & - & $2.378^{\wedge}$ & $2.378^{\wedge}$ & - & - & 0.154 \\
\hline Abruzzo & $1.875^{\wedge}$ & $0.149 \wedge$ & $-0.226^{\wedge}$ & - & - & - & $2.203^{\wedge}$ & $2.203^{\wedge}$ & - & - & 0.341 \\
\hline Molise & $4.030^{\wedge}$ & $0.780^{\wedge}$ & $-0.226^{\wedge}$ & $-3.473^{\wedge}$ & $-0.505^{\wedge}$ & 0.087 & $18.291^{\wedge}$ & $0.767 *$ & $0.274 \wedge$ & -0.139 & 0.416 \\
\hline Campania & $1.989 \wedge$ & $-0.120^{\wedge}$ & $-0.226^{\wedge}$ & - & - & - & $1.776^{\wedge}$ & $1.776^{\wedge}$ & - & - & 0.194 \\
\hline Puglia & $2.133^{\wedge}$ & 0.081 & $-0.226^{\wedge}$ & - & - & - & $2.321^{\wedge}$ & $2.321^{\wedge}$ & - & - & 0.075 \\
\hline Basilicata & - & - & - & - & - & - & - & - & - & - & - \\
\hline Calabria & $8.108^{\wedge}$ & $1.389 \wedge$ & $-0.226 \wedge$ & $-5.581^{\wedge}$ & $-1.915^{\wedge}$ & $0.306^{\wedge}$ & $-20.847 \wedge$ & $1.656^{\wedge}$ & $-0.526^{\wedge}$ & $0.080^{\wedge}$ & 0.796 \\
\hline Sicilia & $1.532^{\wedge}$ & $0.656^{\wedge}$ & $-0.226 \wedge$ & -0.082 & $-0.869 \wedge$ & $0.314^{\wedge}$ & $4.452^{\wedge}$ & $1.195^{\wedge}$ & $-0.213^{\wedge}$ & 0.088 & 0.308 \\
\hline Sardegna & $0.657^{\wedge}$ & $0.717^{\wedge}$ & $-0.226^{\wedge}$ & $3.780^{\wedge}$ & $-1.568 \wedge$ & $0.360^{\wedge}$ & $2.319^{\wedge}$ & $2.397 \wedge$ & $-0.851^{\wedge}$ & $0.134 \wedge$ & 0.224 \\
\hline
\end{tabular}

\footnotetext{
Notes:

$\wedge$ and $*$ indicate, respectively, significant at the $1 \%$ and $5 \%$ level of significance.
} 
APPENDIX

Table A.1 - Unit root tests on $g_{t}$

\begin{tabular}{|c|c|c|c|c|}
\hline \multirow[t]{2}{*}{ Region } & \multicolumn{2}{|c|}{$\mathrm{ADF}$} & \multicolumn{2}{|c|}{ IO2 } \\
\hline & Lags & t-ratio & Lags & t-ratio \\
\hline Piemonte & 0 & $-4.136^{\wedge}$ & - & - \\
\hline Valle d'Aosta & 0 & $-6.180^{\wedge}$ & - & - \\
\hline Lombardia & 0 & $-2.336^{\wedge}$ & 7 & $-5.653 *$ \\
\hline Trentino Alto & 0 & $-9.150^{\wedge}$ & - & - \\
\hline Adige & & & & \\
\hline Veneto & 0 & $-4.147 \wedge$ & - & - \\
\hline Friuli Venezia & 0 & $-3.241 *$ & - & - \\
\hline Giulia & & & & \\
\hline Liguria & 1 & $-8.394 \wedge$ & - & - \\
\hline Emilia & 1 & $-4.500^{\wedge}$ & - & - \\
\hline Romagna & & & & \\
\hline Toscana & 0 & $-4.439 \wedge$ & - & - \\
\hline Umbria & 0 & $-10.120^{\wedge}$ & - & - \\
\hline Marche & 0 & $-4.282^{\wedge}$ & - & - \\
\hline Lazio & 0 & $-3.806^{\wedge}$ & - & - \\
\hline Abruzzo & 0 & $-4.366^{\wedge}$ & - & - \\
\hline Molise & 1 & $-7.745^{\wedge}$ & - & - \\
\hline Campania & 0 & $-4.704 \wedge$ & - & - \\
\hline Puglia & 0 & $-3.939 \wedge$ & - & - \\
\hline Basilicata & 0 & $-3.961 \wedge$ & - & - \\
\hline Calabria & 0 & $-11.740^{\wedge}$ & - & - \\
\hline Sicilia & 0 & $-4.807 \wedge$ & - & - \\
\hline Sardegna & 0 & $-5.918 \wedge$ & - & - \\
\hline
\end{tabular}

Notes:

The IO2 is the "Innovational Outlier" model with a change in the slope and the constant, proposed by Perron (1997) as one of three models for his unit root test with an endogenously selected structural break;

Lags selected with a general-to-simple procedure;

$\wedge$ and $*$ indicate, respectively, significant at the $1 \%$ and $5 \%$

level of significance. 
Table A.2 - OLS estimation of Equation (1)

\begin{tabular}{|c|c|c|c|c|}
\hline Region & $g_{N}$ & $\beta_{3}$ & $R^{2}$ & AR1 \\
\hline Piemonte & 1.932 & $-0.148 * *$ & 0.322 & 2.082 \\
\hline Valle d'Aosta & 1.195 & $-0.092 *$ & 0.215 & 0.183 \\
\hline Lombardia & $2.154 \wedge$ & -0.233 & 0.242 & 1.333 \\
\hline $\begin{array}{l}\text { Trentino Alto } \\
\text { Adige }\end{array}$ & 1.100 & -0.046 & 0.113 & 0.539 \\
\hline Veneto & 3.291 & -0.053 & 0.135 & 2.251 \\
\hline $\begin{array}{l}\text { Friuli Venezia } \\
\text { Giulia }\end{array}$ & 2.007 & -0.085 & 0.063 & $3.509 *$ \\
\hline Liguria & 3.351 & -0.045 & 0.190 & $2.860 * *$ \\
\hline $\begin{array}{l}\text { Emilia } \\
\text { Romagna }\end{array}$ & 1.583 & -0.087 & 0.089 & $2.816^{* *}$ \\
\hline Toscana & 2.975 & -0.058 & 0.232 & 1.118 \\
\hline Umbria & 2.362 & $-0.097 \wedge$ & 0.536 & 2.305 \\
\hline Marche & 0.759 & 0.047 & 0.304 & 0.363 \\
\hline Lazio & $2.679 *$ & -0.155 & 0.381 & 0.415 \\
\hline Abruzzo & -4.856 & -0.009 & 0.339 & 0.924 \\
\hline Molise & 27.446 & -0.012 & 0.108 & 0.012 \\
\hline Campania & 5.421 & -0.198 & 0.391 & $3.078 * *$ \\
\hline Puglia & 81.054 & -0.006 & 0.460 & $5.282 *$ \\
\hline Basilicata & $4.486 *$ & $-0.222 * *$ & 0.685 & 0.343 \\
\hline Calabria & -5.034 & 0.094 & 0.350 & 0.609 \\
\hline Sicilia & $5.742 * *$ & $-0.170 * *$ & 0.470 & $3.077 * *$ \\
\hline Sardegna & -2.513 & 0.064 & 0.333 & 0.808 \\
\hline Average & 6.857 & -0.076 & 0.298 & \\
\hline
\end{tabular}

\section{Notes:}

$\wedge$, * and ** indicate, respectively, significant at the $1 \%$, $5 \%$ and $10 \%$ level of significance. 
Table A.3 - OLS estimation of Equation (2)

\begin{tabular}{|c|c|c|c|c|}
\hline Region & $g_{N}$ & $\beta_{3}$ & $R^{2}$ & AR1 \\
\hline Piemonte & $1.730^{\wedge}$ & -0.532 & 0.254 & 1.304 \\
\hline Valle d'Aosta & $1.545^{\wedge}$ & -0.704 & 0.157 & 0.011 \\
\hline Lombardia & $2.117 \wedge$ & $-0.807^{*}$ & 0.391 & 1.519 \\
\hline $\begin{array}{l}\text { Trentino Alto } \\
\text { Adige }\end{array}$ & $2.655^{\wedge}$ & -0.604 & 0.098 & 0.184 \\
\hline Veneto & $2.641^{\wedge}$ & -0.295 & 0.054 & 1.967 \\
\hline $\begin{array}{l}\text { Friuli Venezia } \\
\text { Giulia }\end{array}$ & $2.366^{\wedge}$ & -0.732 & 0.094 & 1.137 \\
\hline Liguria & $1.871^{\wedge}$ & -0.401 & 0.119 & 1.036 \\
\hline $\begin{array}{l}\text { Emilia } \\
\text { Romagna }\end{array}$ & $2.263^{\wedge}$ & -0.950 & 0.124 & $3.548 *$ \\
\hline Toscana & $1.898^{\wedge}$ & -0.310 & 0.134 & 0.617 \\
\hline Umbria & $2.383^{\wedge}$ & -1.008 & 0.130 & 0.032 \\
\hline Marche & $2.074 \wedge$ & 0.306 & 0.097 & 0.933 \\
\hline Lazio & $2.418^{\wedge}$ & -0.441 & 0.271 & 0.432 \\
\hline Abruzzo & $2.647 \wedge$ & -0.034 & 0.287 & 2.486 \\
\hline Molise & $2.622^{\wedge}$ & -0.093 & 0.080 & 0.400 \\
\hline Campania & $2.183^{\wedge}$ & $-0.211^{* *}$ & 0.193 & 0.490 \\
\hline Puglia & $2.198^{\wedge}$ & -0.013 & 0.209 & 2.094 \\
\hline Basilicata & $2.392^{\wedge}$ & -0.620 & 0.243 & 1.079 \\
\hline Calabria & $1.429 \wedge$ & 0.205 & 0.170 & 14.388 \\
\hline Sicilia & $2.406^{\wedge}$ & -0.372 & 0.191 & $2.764^{* *}$ \\
\hline Sardegna & $1.774 \wedge$ & 0.098 & 0.087 & 0.686 \\
\hline Average & 2.181 & -0.376 & 0.169 & \\
\hline
\end{tabular}

Notes:

$\wedge$, * and ** indicate, respectively, significant at the $1 \%$, $5 \%$ and $10 \%$ level of significance. 